there must be many intersections with so high a porosity, and the Johnson-Stewart model neglects the volume of these intersections .

It is concluded that application of the Johnson-Stewart method for predicting diffusion rates may be hazardous for porous materials either containing abnormally small pores or having abnormally high porosities. For materials having pore structures of types more frequently encountered, the behavior of the Harshaw alumina reinforces previous conclusions of reasonable a priori predictability and good extrapolation properties with pressure.

It may also be noted that the effect of temperature on the predictive capability of the Johnson-Stewart method was very slight.

\section{ACKNOWLEDGMENTS}

Porous materials were donated by Mr. D. H. Weitzel of the National Bureau of Standards, Boulder, Colorado; the Harshaw Chemical Company; and the Pigments Division of Degussa, Inc. During his study at the University of Colorado, Mr. Omata was supported by Mitsui Toatsu Chemicals.

\section{LITERATURE CITED}

Brown, L. F., et al., "The Prediction of Diffusion Rates in
Porous Materials at Different Pressures," J. Catalysis, 14, 220 (1969)

Haynes, H. W., Jr., "Models for Predicting the Diffusion Rates of Gases in Porous Catalysts and Adsorbents," Ph.D. Thesis, Univ. Colorado, Boulder (1969)

- ., and L. F. Brown, "Effect of Pressure on Predicted and Observed Diffusion Rates in Constricted Pores-A Theoretical Study," AIChE J., 17, 491 (1971).

Johnson, M. F. L., and W. E. Stewart, "Pore Structure and Gaseous Diffusion in Solid Catalysts," J. Catalysis, 4, 248 (1965).

Omata, H., "Diffusion Rates of Gases in Porous Catalysts and Adsorbents Containing Small Pores," M.S. Thesis, Univ. Colorado, Boulder (1971).

_., and L. F. Brown, "Using the Dusty Gas Diffusion Equation in Catalyst Pores Smaller Than 50 A Radius," AIChE J., 18, 000 (1972).

Satterfield, C. N., and P. J. Cadle, "Diffusion in Commercially Manufactured Pelleted Catalysts," Ind. Eng. Chem. Process Design Develop., 7, 257 (1968a).

_.." "Gaseous Diffusion and Flow in Commercial Catalysts at Pressure Levels above Atmospheric," Ind. Eng. Chem. Fundamentals, 7, 202 (1968b).

Weitzel, D. H., and W. V. Loebenstein, "Conversion of Orthoto Parahydrogen," U.S. Patent 2,943,917 (July 5, 1960).

Manuscript received May 15, 1972; paper accepted June 7, 1972.

\title{
Impact Tube Gas Velocity Measurement at High Temperatures
}

\author{
F. E. CARLETON and R. H. KADLEC
}

\author{
University of Michigan, Department of Chemical Engineering
}

Ann Arbor, Michigan 48104

Impact tubes (Pitot tubes) are frequently used to determine the line or velocity of a flowing fluid at a point. The inviscid model, or Bernoulli equation, can be successfully applied in gas flows at reasonable temperatures, but when extremely high temperatures are encountered this model becomes suspect. Because gas viscosities increase with temperature, and because of compressibility effects, the usual impact tube results no longer apply.

When temperatures exceed those normally found in flames $(1,000-2,000 \mathrm{~K})$, such conditions may be encountered. The impact tube must then be internally cooled, or destruction will result. Thus the phenomenon of heat transfer also enters the picture. A model of an impact tube must correctly predict both heat and momentum transfer when the cooled tube is immersed in an extremely hot gas (plasma).

\section{STAGNATION STREAMLINE FLOW}

For isentropic, inviscid deceleration of an incompressible fluid along a stagnation streamline, the stagnation pressure $P_{0}$ as measured with an impact (Pitot) tube is

Correspondence conceming this note should be addressed to $R$. H. Kadlec. F. E. Carlton is with the Atlantic Richfield Company, Dallas, Texas. given in terms of the free stream quantities-static pressure $P_{x}$, density $\rho_{x}$, and velocity $U$-by the Bernoulli equation

$$
P_{0}=P_{\infty}+\frac{\rho_{\infty} U^{2}}{2}
$$

If the fluid is compressible, the equation for isentropic, inviscid deceleration becomes

$$
P_{0}=P_{\infty}\left(1+\frac{\gamma-1}{2} M_{\infty}^{2}\right) \frac{\gamma-1}{\gamma}
$$

where $M_{x}$ is the free stream Mach number and $\gamma$ is the ratio of specific heats $C_{p} / C_{v}$.

For viscous fluids flowing at Reynolds numbers above 100 (the characteristic length chosen to be the radius of the impact tube), the viscous forces acting on the fluid are very small in comparison to the inertia forces and the above equations are valid. As the Reynolds number is decreased below 100, however, the measured impact pressure departs from the true stagnation pressure based on isentropic, inviscid deceleration, and it is no longer possible to ignore the effects of viscosity. This departure of the impact pressure from the Bernoulli pressure is known as the Barker (1922) effect and has been observed experimentally by Hurd (1953), MacMillian (1954), Schowalter and Blaker (1961), and Sherman (1953). It shows 
itself in the form of an additional pressure which can be calculated for simple geometries (that is, cylinders, spheres), so that the measured impact pressure is greater than the Bernoulli pressure.

Carleton (1970) has shown that the difference between the measured impact pressure and the free stream pressure $P_{0}-P_{\infty}$ for a plasma flowing around a hemispherical tipped cylindrical body can be expressed by a Bernoulli term, a compressibility term, and a viscous term:

$$
P_{0}-P_{\infty}=\frac{\rho_{\infty} U^{2}}{2}+\frac{\rho_{\infty}^{2} U^{4}}{8 \gamma P_{\infty}}+\frac{2 \bar{\mu} U}{R\left(1+\frac{0.5576}{\sqrt{R e}}\right)}
$$

Physical properties in the first two terms are evaluated at free stream conditions of temperature and pressure. In order to select $\vec{\mu}$ and evaluate $R e$ in the third term, a characteristic temperature of the boundary layer is chosen. This characteristic or reference temperature is a temperature at which constant property results will closely approximate true variable property behavior. The appropriate values of $\bar{\mu}$ and $R e$ are those corresponding to the reference temperature. Although no prior basis for the use of this technique in a plasma boundary layer has been established, it is a method which does compensate for the temperature gradient near the probe. Chambre and Smith (1949) in a similar manner developed an expression for a high velocity low density gas stream which differs somewhat from Equation (3) in the viscous term because flow around a spherical body was assumed.

\section{STAGNATION POINT HEAT TRANSFER}

The validity of using the reference temperature technique in plasma flow calculations is established by considering heat transfer to an object immersed in a plasma stream and applying the resulting theoretical expression to previously unresolved experimental data. In order to determine heat transfer rates at the stagnation point of the object, the equations describing the flow in the boundary layer surrounding the object must be analyzed.

Thus, by assuming the fluid properties constant, evaluated at the reference conditions, the system of boundary layer equations becomes

$$
\begin{gathered}
r \frac{\partial u}{\partial z}+\frac{\partial}{\partial r}(r v)=0 \\
\rho^{*}\left(v \frac{\partial v}{\partial r}+u \frac{\partial v}{\partial z}\right)=-\frac{\partial P}{\partial r}+\mu^{*} \frac{\partial^{2} v}{\partial z^{2}} \\
\rho^{*}\left(C_{P}+C_{P r}\right)\left(v \frac{\partial T}{\partial r}+u \frac{\partial T}{\partial z}\right)=\left(K+K_{r}\right) \frac{\partial^{2} T}{\partial z^{2}}
\end{gathered}
$$

In the above equations denotes reference conditions. Sibulkin (1952), following the method of Squire, given by Goldstein (1938), and using Homann's (1952) stagnation point solution of the momentum equation, obtained a solution to the above system of equations for laminar, incompressible low speed flow. In dimensionless form the heat transfer coefficient is given by

$$
\begin{array}{r}
h=\frac{0.763\left(K+K_{r}\right)^{*}}{R}\left[\frac{\left(C_{p}+C_{P r}\right)^{*} \mu^{*}}{\left(K+K_{r}\right)^{*}}\right]^{0.4} \\
{\left[\frac{\rho^{*} R U}{\mu^{*}}\right]^{0.5}}
\end{array}
$$

where $R$ is the radius of the half body, $U$ the free stream approach velocity, and all fluid properties are evaluated at the reference temperature. This is taken to be the temperature corresponding to the mean boundary layer enthalpy:

$$
h^{\star} \equiv h_{w}+0.5\left(h_{\infty}-h_{w}\right)
$$

\section{VERIFICATION OF HEAT TRANSFER MODEL}

To demonstrate the applicability of the reference temperature method to plasma flow problems, Equation (7) was used to resolve the data of Chludzinski (1964). Chludzinski studied heat transfer to solids immersed in an r.f. generated plasma at atmospheric pressure. Heat transfer coefficients were determined from the dynamic response of shielded thermocouples exposed to an argon plasma for time periods of approximately $0.1 \mathrm{sec}$. The thermocouple was housed within a water-cooled probe and was advanced to the probe stagnation point and retracted by means of solenoids mounted above the cooling water jacket.

The theoretical predictions of $h$ obtained by using Equation (7) for the three probe sizes are plotted in Figure 1 as a function of the free stream value of $\alpha$, the degree of argon ionization. The range of $\alpha$ corresponds to the free stream temperature range of $8,500 \mathrm{~K}$ to $10,500 \mathrm{~K}$. The temperature scale, which is not linear, is indicated.

\section{CONFIRMATION OF PRESSURE RECOVERY MODEL}

To test the model for pressure recovery at the stagnation point of a cool impact probe in a plasma stream, experimental results must be considered. In a recent study of Carleton (1970), flow patterns in a confined argon plasma jet, profiles of impact pressure, and temperature were obtained in the jet at two argon flow rates. Velocity profiles were then calculated. The pressure profiles were measured with a water-cooled impact probe which moved continuously through the jet along the jet diameter. Property data were taken from Devoto $(1966,1967)$, Drellishak (1963), Meador and Stratton (1965) and Sherman (1963).

A check on the values obtained for the velocities in the two plasma jets is obtained by integrating the velocity profile to determine the mass flow rate. The calculated value can then be compared with the metered argon flow rate to the plasma generator. For the two jets, the veloci-

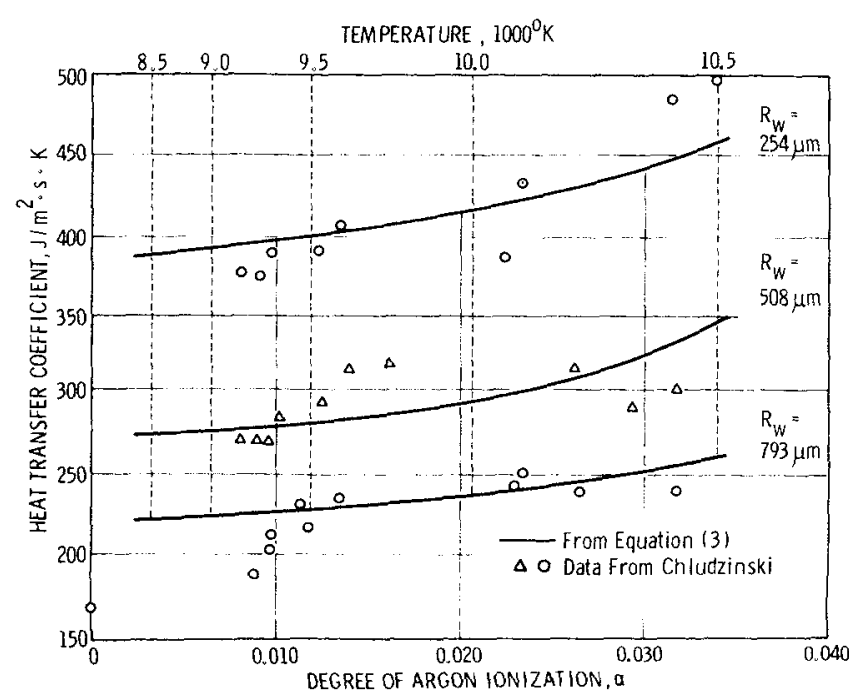

Fig. 1. Calculated and observed heat transfer coefficients as a function of the degree of argon ionization. 
Table 1. EFfect of Viscosity and Compressibility on Plasma Veloctrtes

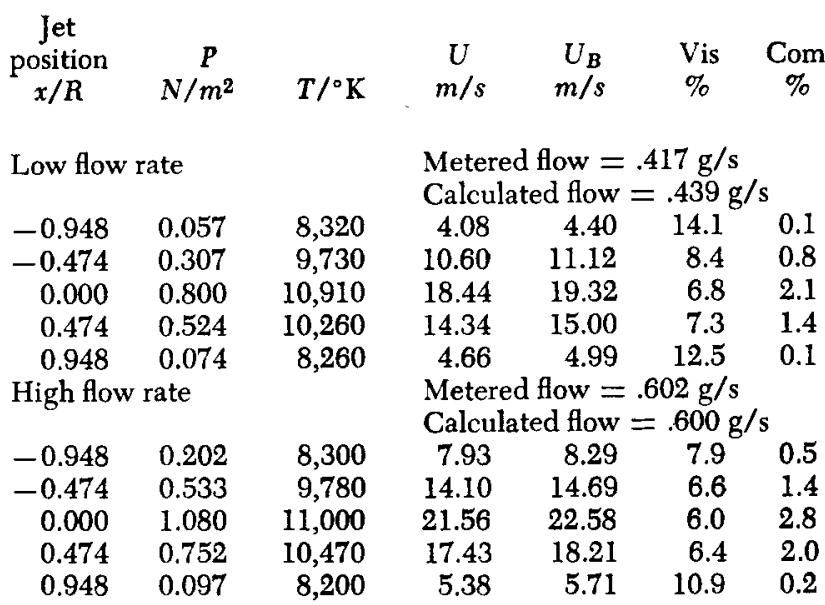

ties at each point on the profile were multiplied by the corresponding density and area and summed. The area used for each velocity zone was that of a half annular shell of the appropriate mean radius. Since the velocities were indicated only for the luminous region which is slightly smaller than the region of momentum exchange, the temperature profiles were extrapolated linearly to calculate velocities at the fringes of the impact pressure profiles. Two additional values were obtained in this manner at each edge. The results are presented in Table 1.

The effects of compressibility and viscosity on the velocity measurements in each plasma jet, for five locations along the velocity profile, is indicated in Table $I$ for two flow rates. The impact pressure, the temperature, the actual velocity, the Bernoulli velocity, and contributions of the viscosity and compressibility terms of Equation (3) to the measured impact pressure are listed.

\section{CONCLUSIONS}

A model has been developed to relate the pressure sensed by a water-cooled impact probe in a plasma flow field to the free stream plasma velocity. The model considers the effects of both viscosity and heat transfer. The model was applied to determine velocity profiles in a plasma jet. Integration of the velocity profiles yielded mass flow rates which agreed closely with the metered flow rates to the plasma generator. Heat transfer to the probe is also predicted well.

\section{ACKNOWLEDGMENTS}

This research was supported in part by a grant from the National Science Foundation.

\section{NOTATION}

$C_{p}=$ specific heat capacity at constant pressure, $\mathrm{J} / \mathrm{kg} \cdot \mathbf{K}$

$C_{P r}=$ reactive heat capacity at constant pressure, $\mathrm{J} /$ $\mathrm{kg} \cdot \mathrm{K}$

$C_{v}=$ specific heat capacity at constant volume, $\mathrm{J} / \mathrm{kg} \cdot \mathrm{K}$

Com $=$ contribution of the compressibility term in Equation (3) to the measured impact pressure, $\%$

$h=$ specific enthalpy, $\mathrm{J} / \mathrm{kg}$

$h=$ heat transfer coefficient, $\mathrm{J} / \mathrm{m}^{2} \cdot \mathrm{s} \cdot \mathrm{K}$

$K=$ thermal conductivity, $\mathrm{J} / \mathrm{m} \cdot \mathrm{s} \cdot \mathrm{K}$

$K_{r}=$ reactive thermal conductivity at constant pressure, $\mathrm{J} / \mathrm{m} \cdot \mathrm{s} \cdot \mathrm{K}$

$M=$ Mach number
$P \quad=$ pressure, $\mathrm{N} / \mathrm{m}^{2}$

$r=$ coordinate normal to the stagnation streamline, $\mathbf{m}$

$R=$ radius of curvature of a spherical half body, $\mathrm{m}$

Re = Reynolds number

$T=$ temperature, $\mathrm{K}$

$u=$ component of velocity parallel to the stagnation streamline, $\mathrm{m} / \mathrm{s}$

$U=$ axial component of the free stream velocity, $\mathrm{m} / \mathrm{s}$

$v=$ component of velocity normal to the stagnation streamline, $\mathrm{m} / \mathrm{s}$

Vis $=$ contribution of the viscosity term in Equation (3)

$z \quad=$ coordinate parallel to the stagnation streamline, $\mathrm{m}$

$\alpha=$ fraction of argon which is ionized

$\mu \quad=$ viscosity, $\mathrm{kg} / \mathrm{m} \cdot \mathrm{s}$

$\rho \quad=$ mass density, $\mathrm{kg} / \mathrm{m}^{3}$

$\gamma \quad=$ heat capacity ratio

\section{Subseripts}

$0=$ stagnation conditions

$\infty=$ free stream conditions

$w \quad=$ wall conditions

\section{Superseripts}

- $=$ mean value

* $\quad=$ reference conditions

\section{LITERATURE CITED}

Barker, Muriel, "On the Use of Very Small Pitot Tubes for Measuring Wind Velocity," Proc. Royal Soc., Ser. A, 101, 435 (1922).

Carleton, F. E., "Flow Patterns in a Confined Plasma Jet," Ph.D. thesis, Univ. Michigan, Ann Arbor (1970).

Chambre, T. L., and H. R. Smith, "The Impact Tube in a Viscous Compressible Gas," Univ. California Eng. Projects Report HE-150-63, Berkeley (1949).

Chludzinski, G. R., "Energy Transfer To Solids in R. F. Generated Plasmas," Ph.D. thesis, Univ. Michigan, Ann Arbor (1964).

Devoto, R. S., "Transport Properties of Ionized Monatomic Gases," Phys. Fluids, 9, 1230 (1966).

-., "Transport Coefficients of Partially Ionized Argon," ibid., 10, 354 (1967).

Drellishak, K. S., et al., "Partition Functions and Thermodynamic Properties of Argon Plasmas," Arnold Eng. Devt. Center AEDC-TDR-63-146 (1963).

Goldstein, S., (ed.), Modern Developments in Fluid Dynamics, Vol. II, Clarendon Press, Oxford (1938).

Homann, F., "The Effect of High Viscosity on the Flow Around a Cylinder and Around a Sphere," National Advisory Comm. for Aeron. TM 1334 ( 1952 ).

Hurd, C. W., et al., "Influence of Viscous Effects on Impact Tubes," J. Appl. Mech., 20, 253 (1953).

MacMillian, F. A., "Viscous Effects on Pitot Tubes at Low Speeds," J. Royal Aeron. Soc., 58, 570 (1954).

Meador, W. E., and L. D. Stratton, "Electrical and Thermal Properties of Plasmas," Phys. Fluids, 8, 1694 (1965).

Schowalter, W. R., and G. E. Blaker, "On the Behavior of Impact Probes at Low Reynolds Numbers," J. Appl. Mech., 28, 136 (1961).

Sherman, F. S., "New Experiments on Impact-Pressure Interpretation in Supersonic and Subsonic Rarefied Air Streams," National Advisory Comm. for Aeron. TN 2995 (1953).

-., and J. Grey, "Calculation of Transport Properties for Mixtures of Helium and Partly-Ionized Argon," Princeton Univ. Aeron. Eng. Lab. Report No. 673 ( 1963 ).

-., "Interactions Between a Partly-Ionized Laminar Subsonic Jet and a Cool Stagnant Gas," ibid., No. 707 (1964).

Sibulkin, M., "Heat Transfer Near the Forward Stagnation Point of a Body of Revolution," J. Aeron. Sci., 19, 570 (1952).

Manuscript received May 31, 1972; revision received June 12, 1972; note accepted June 13, 1972. 